\title{
Peningkatan Sulforafan Brokoli (Brassica oleraceae L. var italica) Dengan Modifikasi Media Pada Kultur Jaringan
}

\author{
Marhaenus J. Rumondor ${ }^{a *}$, Jeany Mandang ${ }^{b}$, Wiske Rotinsulu ${ }^{b}$ \\ aJurusan Biologi, FMIPA, Unsrat, Manado \\ bJurusan Budidaya Pertanian, Fakultas Pertanian, Unsrat, Manado
}

\begin{tabular}{l} 
K A T A K U N \\
\hline Sulforafan \\
Metionin \\
Ekstrak benih \\
Brokoli
\end{tabular}

$\overline{\text { KEYWORDS }}$

Sulphoraphane

Methionine

Seed extract

Brocoli

\begin{tabular}{l}
$\overline{\text { AVAILABLE ONLINE }}$ \\
\hline 12 February 2013 \\
\hline
\end{tabular}

\begin{abstract}
A B S T R A K
Penelitian ini menggunakan metode percobaan rancangan faktorial dalam rancangan acak lengkap dengan perlakuan metionin 3 taraf, yaitu 0 ppm (M0), 10 ppm (M10), 20 ppm (M20), dan ekstrak benih brokoli dengan 4 taraf, yaitu 0 g/l (E0), 1 g/l (E1), 2 g/l (E2), 3 g/l (E3), yang diulang sebanyak 3 kali. Variabel yang diamati terdiri dari jumlah tunas, berat basah tunas, tinggi tunas, jumlah daun, dan kandungan sulforafan. Data diuji dengan analisis sidik ragam, dilanjutkan dengan uji BNT. Hasil penelitian ini menunjukkan bahwa perlakuan metionin memberi pengaruh yang nyata untuk variabel jumlah tunas, tinggi tunas, dan jumlah daun; dan berpengaruh yang sangat nyata untuk variabel berat basah tunas dan kandungan sulforafan. Perlakuan ekstrak benih brokoli tidak memberi pengaruh yang nyata pada variabel jumlah tunas, berat basah tunas, tinggi tunas, dan jumlah daun; berpengaruh yang sangat nyata untuk variabel kandungan sulforafan. Kombinasi perlakuan metionin dan ekstrak benih brokoli berpengaruh yang nyata pada variabel jumlah tunas, berpengaruh yang sangat nyata pada variabel kandungan sulforafan, dan tidak berpengaruh yang nyata pada variabel berat basah tunas, tinggi tunas, dan jumlah daun. Kandungan sulforafan tertinggi dicapai pada kombinasi perlakuan metionin 10 ppm dengan 3 gram ekstrak benih (M10E3).

\begin{tabular}{l}
\hline A B S T R A C T \\
\hline This research was using factorial design in complete random design \\
with three level methionine there was $0 \mathrm{ppm}(\mathrm{M} 0), 10 \mathrm{ppm}(\mathrm{M} 10), 20 \mathrm{ppm}$ \\
(M20) and four level extract brocoli seeds, was $0 \mathrm{~g} / \mathrm{I}(\mathrm{EO}), 1 \mathrm{~g} / \mathrm{I}(\mathrm{E} 1), 2 \mathrm{~g} / \mathrm{I}$ \\
(E2), and $3 \mathrm{~g} / \mathrm{I}(\mathrm{E} 3)$, become 12 treatment combinations with 3 replicated. \\
The variable that was observed are the total of shoot, wet weight of shoot, \\
the shoot length, total leave, and the sulphoraphane content. The data \\
was examine with analyze of varians and continue with LSD (Least \\
Significant Difference). The result of this research shown that application \\
of methionine have significance to the total shoot, shoot length, and total \\
leave; more significance to wet weight shoot and sulphoraphane content. \\
Application of extract seeds was non significant to the total shoot, wet \\
weight shoot, shoot length, an total leave; more significant to \\
sulphoraphane content. Application combination of methionine and \\
extract seeds of brocoli was significant to the total shoot, more significant \\
to sulphoraphane content, and non significant to wet weight shoot, shoot \\
length, and total leave. The high sulphoraphane amount was in the \\
application of methionine 10 ppm and 3 g/l seed extract (M10E3). \\
\hline
\end{tabular}

This research was using factorial design in complete random design with three level methionine there was 0 ppm (M0), 10 ppm (M10), 20 ppm (M20) and four level extract brocoli seeds, was $0 \mathrm{~g} / \mathrm{I}$ (E0), $1 \mathrm{~g} / \mathrm{I}$ (E1), $2 \mathrm{~g} / \mathrm{I}$ (E2), and $3 \mathrm{~g} / \mathrm{I}$ (E3), become 12 treatment combinations with 3 replicated. The variable that was observed are the total of shoot, wet weight of shoot, the shoot length, total leave, and the sulphoraphane content. The data was examine with analyze of varians and continue with LSD (Least of methionine have significance to the total shoot, shoot length, and total leave; more significance to wet weight shoot and sulphoraphane content. Application of extract seeds was non significant to the total shoot, wet weight shoot, shoot length, an total leave; more significant to sulphoraphane content. Application combination of methionine and extract seeds of brocoli was significant to the total shoot, more significant length, and total leave. The high sulphoraphane amount was in the
\end{abstract}

*Corresponding author: Jurusan Biologi FMIPA UNSRAT, Jl. Kampus Unsrat, Manado, Indonesia 95115; Email address: marhaenusrumondor66@yahoo.com Published by FMIPA UNSRAT (2013) 


\section{Pendahuluan}

Salah satu tanaman suku kubis-kubisan atau Brassicaceae yang merupakan tanaman sayuran adalah brokoli (Brassica oleracea L. var Italica), yang mengandung lemak, protein, karbohidrat, serat, air, zat besi, kalsium, mineral dan bermacam-macam vitamin seperti $A, C, E$, riboflavin, dan nikotin-amide, juga mengandung sulforafan, yaitu suatu senyawa pencegah penyakit kanker. Karena itu sayuran brokoli ini dinobatkan sebagai tanaman obat (Anonim, 2009).

Sulforafan merupakan senyawa antioksidan paling ampuh yang tersimpan, selain betakaroten, indola, kuersetin, dan glutation. Brokoli juga sangat kaya akan mikromineral kromium, yang membantu meredam melonjaknya kadar gula darah pada penderita kencing manis (Diabetes mellitus), sehingga pemanfaatan sayuran brokoli ini sangat disarankan untuk penderita kencing manis. Brokoli berkhasiat mempercepat penyembuhan penyakit serta mencegah dan menghambat perkembangan sel-sel kanker di dalam tubuh, terutama penyakit kanker yang berkaitan dengan hormon, seperti kanker payudara pada kaum perempuan dan kanker prostat yang mengancam pria (Dharlimantha, 2007).

Sebagai tanaman yang baru dibudidayakan di Indonesia, yaitu sejak tahun 1970-an, perlu kiranya perhatian yang cukup besar bagi para ilmuwan terutama pemulia tanaman. Hal ini berkaitan dengan pembentukan jenis baru yang dapat menyediakan bibit sendiri tanpa tergantung dari negara lain yang berdampak pada penghematan biaya untuk pengadaan bibit tersebut (Sowy, 1984).

Metode perbanyakan bibit secara nonkonvensional atau secara in-vitro/kultur jaringan merupakan teknik perbanyakan yang tepat untuk diterapkan karena mampu menumbuhkan sel-sel yang berasal dari tanaman induk pada suatu media buatan secara aseptik untuk mendapatkan tunas atau bakal tanaman baru. Keuntungan yang lain adalah metode ini tidak tergantung pada iklim, bebas hama dan penyakit, dan tidak membutuhkan lahan yang besar (Fowler, 1983). Metode kultur jaringan juga merupakan suatu upaya mengoptimalkan lingkungan tumbuh tanaman. Karena itu perlu diteliti pembiakan vegetatif melalui metode kultur jaringan yang bermanfaat dalam mempertahankan sifat induknya dan dapat menyediakan bibit yang bermutu dalam jumlah yang banyak dengan waktu yang relatif singkat.

Sehubungan dengan fungsi tanaman Brokoli ini sebagai tanaman obat yang mengandung metabolit sekunder, terutama sulforafan, maka perlu kiranya dikembangkan, yang ditujukan pada peningkatan sulforafan dalam kultur yang terkait dengan pengaruh perangsangan zat pengatur tumbuh. Menurut Ding, et al. (2006), sulforafan dibentuk dari metionin dan glukorafanin yang merupakan prazat atau prekursor terhadap sulforafan.

Penelitian ini bertujuan untuk mendapatkan konsentrasi metionin, ekstrak benih brokoli dan kombinasi keduanya yang terbaik dalam pertumbuhan planlet, juga untuk mendapatkan konsentrasi metionin, ekstrak benih brokoli dan kombinasi keduanya yang terbaik dalam peningkatan sulforafan plantlet..

\section{Bahan dan Metode}

\section{1 Alat dan Bahan}

Peralatan yang digunakan dalam penelitian ini adalah laminar air flow cabinet, otoklaf, freezer, oven, ruang kultur, magnetic stirrer, rotary evaporator, $\mathrm{pH}$ meter, perangkat liquid chromatography mass spectroscopy, neraca analitik, detector, sonicleaner, hot plat, sentrifuga, mortal, alat-alat gelas lainnya, timbangan, pipet ukur, botol kaca, pinset, lampu bunsen, pengaduk, dan alat tulis menulis.

Bahan-bahan yang digunakan adalah komponen media MS, NAA, BAP, agar, sukrosa, dan hipokotil kecambah brokoli, kalus, tunas dan plantlet serta senyawa kimia untuk ekstraksi seperti methanol p.a, acetonitril, metal asetat, asam asetat p.a, n-Heksana p.a , amoniak p.a, kloroform p.a, Kristal $\mathrm{Na}_{2} \mathrm{SO}_{4}$, reagen Dragendorf, akuades, standart sulforafan, alkohol, dan ekstrak brokoli.

\section{2 Prosedur Penelitian}

Prosedur penelitian yang dilakukan meliputi :

1. Sterilisasi alat dan pembuatan larutan stok.

2. Pembuatan media MS tanpa perlakuan.

3. Sterilisasi lingkungan kultur dan penanaman eksplan ke medium MS tanpa perlakuan.

4. Pembuatan medium MS yang diberi NAA dan $\mathrm{BAP}+$ metionin +ekstrak benih Brokoli.

5. Penanaman Eksplan tunas.

6. Pengamatan dan Analisis Sulforafan.

7. Analisis Data.

\section{3 Metode Penelitian}

Adapun rancangan yang digunakan ialah rancangan faktorial dalam rancangan acak lengkap yaitu : kombinasi antara metionin dalam tiga taraf dan ekstrak benih brokoli dalam empat taraf dosis (Tabel 1). Masing-masing perlakuan terdiri dari 3 ulangan, sehingga didapatkan 12 kombinasi perlakuan. Analisis sulforafan 3 kali ulangan per perlakuan.

Data diamati pada minggu ke delapan sesudah kultur, kemudian dianalisis secara analisis ragam dan dilanjutkan dengan uji BNT $5 \%$. Variabel yang diamati meliputi jumlah tunas, berat basah tunas, tinggi tunas, jumlah daun, dan kandungan sulforafan. 
Tabel 1. Perlakuan Metionin dan Ekstrak Benih Brokoli yang Diberikan

\begin{tabular}{cc}
\hline Metionin (ppm) & $\begin{array}{c}\text { Ekstrak benih } \\
\text { brokoli (g) }\end{array}$ \\
\hline Mo $=0$ & Eo $=0$ \\
$M 1=10$ & E1 $=1$ \\
$M 2=20$ & E2 $=2$ \\
& E3 $=3$ \\
\hline
\end{tabular}

Data dikumpulkan, ditabulasi dan dianalisis secara statistik untuk penarikan kesimpulan. Data hasil penelitian disajikan dalam bentuk tabel. Uji statistik untuk mengetahui kandungan sulforafan pada kalus dan tunas dilakukan dengan analisis variasi (ANOVA) dalam Rancangan Acak Lengkap. Apabila berbeda maka dilanjutkan dengan Uji BNT $5 \%$.

\section{Hasil dan Pembahasan}

\section{1 Jumlah Tunas}

Hasil pengamatan jumlah tunas disajikan pada Tabel 2.

Tabel 2. Nilai Rataan Interaksi Metionin dan Ekstrak Benih terhadap Jumlah Tunas

\begin{tabular}{|c|c|c|c|c|c|c|}
\hline \multirow{2}{*}{$\begin{array}{l}\text { Metionin } \\
(\mathrm{ppm})\end{array}$} & $0(\mathrm{EO})$ & $1(\mathrm{E} 1)$ & $2(\mathrm{E} 2)$ & 3 (E3) & \multirow[b]{2}{*}{ Total } & \multirow[b]{2}{*}{ Rataan } \\
\hline & \multicolumn{4}{|c|}{ Jumlah Tunas (tunas) } & & \\
\hline 0 (MO) & 9,56 bcd & $11,11^{\mathrm{cd}}$ & $13,44^{d}$ & $11,44 \mathrm{~cd}$ & 45,55 & 11,39 \\
\hline 10 (M10) & $12,00^{d}$ & $9,56 \mathrm{bcd}$ & 6,00 ab & $5,00^{a}$ & 32,56 & 8,14 \\
\hline 20 (M20) & $4,94^{\mathrm{a}}$ & 6,22 ab & $7,56 \mathrm{abc}$ & $9,94 \mathrm{bcd}$ & 28,66 & 7,17 \\
\hline Total & 26,50 & 26,89 & 27,00 & 26,38 & & \\
\hline Rataan & 8,83 & 8,96 & 9,00 & 8,79 & & \\
\hline BNT $5 \%$ & 4,15 & & & & & \\
\hline
\end{tabular}

Tabel 2 di atas terlihat bahwa, interaksi perlakuan pemberian metionin dan ekstrak benih brokoli berbeda nyata berdasarkan analisa sidik ragam. Hal ini diduga bahwa penambahan metionin sebagai prekursor pada media kultur meskipun dapat meningkatkan produksi metabolit sekunder, tapi dapat pula mengakibatkan pertumbuhan selnya rendah (Pandiangan dan Tilaar, 2007). Beberapa penelitian yang telah dilakukan sebelumnya, seperti produksi katarantin tapak dara yang meningkat dengan pemberian tryptophan, tidak diikuti dengan pertumbuhan tanaman itu sendiri. Pertumbuhan sel yang rendah karena pertumbuhannya dijebak lambat, agar supaya produksi metabolit sekunder bisa meningkat. Sel tanaman dalam pertumbuhannya memerlukan unsur-unsur seperti karbon $(\mathrm{C})$, nitrogen $(\mathrm{N})$, hidrogen $(\mathrm{H})$, oksigen $(\mathrm{O})$, dan belerang $(\mathrm{S})$, yang mana unsur-unsur tersebut juga merupakan penyusun metionin.

Penambahan ekstrak benih brokoli tidak berpengaruh yang nyata, terlihat dari data yang ada relatif datar. Hal ini diduga bahwa ekstrak benih yang diberikan tidak membantu dalam proses pertumbuhan jumlah tunas karena di dalam benih relatif kurang memiliki unsur-unsur yang diperlukan dalam pertumbuhan khususnya jumlah tunas. Hal ini lebih jelas terlihat pada penambahan ekstrak benih brokoli sebanyak 3 gram (E3), terjadi penurunan jumlah tunas.
Kombinasi perlakuan metionin dan ekstrak benih brokoli memberi hasil yang berpengaruh nyata. Hal ini mungkin terjadi karena pengaruh metionin masih besar meskipun dikombinasikan dengan ekstrak benih brokoli, atau mungkin setelah metionin berinteraksi dengan ekstrak benih brokoli terjadi kombinasi yang baik untuk pertumbuhan jumlah tunas. Pertumbuhan jumlah tunas yang tertinggi dicapai pada kombinasi perlakuan tanpa metionin dan ektrak benih brokoli $2 \mathrm{~g} / \mathrm{l}$ (MOE2), dan yang terendah pada kombinasi perlakuan metionin 20 ppm dan tanpa ekstrak benih brokoli (M20E0).

\section{2 Berat Basah Tunas}

Variabel pengamatan berat basah tunas tersaji pada Tabel 3. Pada Tabel 3 terlihat bahwa hasil analisis statistik perlakuan pemberian metionin memberi pengaruh yang sangat nyata pada variabel berat basah tunas. Pemberian ekstrak benih brokoli tidak berpengaruh yang nyata, begitupun dengan kombinasi metionin dan ekstrak benih brokoli tidak berpengaruh yang nyata pada variabel berat basah tunas. Perbedaan yang nyata di sini menunjuk pada pengaruh yang negatif. Penambahan metionin justru menurunkan berat basah tunas. 
Tabel 3. Nilai Rataan Interaksi Metionin dan Ekstrak Benih terhadap Berat Basah Tunas

\begin{tabular}{|c|c|c|c|c|c|c|}
\hline Ekstrak & $O(E 0)$ & 1 (E1) & $2(\mathrm{E} 2)$ & 3 (E3) & \multirow[b]{2}{*}{ Total } & \multirow[b]{2}{*}{ Rataan } \\
\hline Metionin & \multicolumn{4}{|c|}{ Berat Basah Tunas (mg) } & & \\
\hline 0 (M0) & 0,46 a & 0,39 a & $0,78^{b}$ & $0,76^{b}$ & 2,39 & 0,59 \\
\hline 10 (M10) & $0,62^{b}$ & 0,35 a & $0,31^{a}$ & $0,49 \mathrm{~b}$ & 1,77 & 0,44 \\
\hline 20 (M20) & 0,24 a & 0,22 a & 0,22 a & 0,12 a & 0,80 & 0,20 \\
\hline Total & 1,32 & 0,96 & 1,31 & 1,37 & & \\
\hline Rataan & 0,44 & 0,32 & 0,44 & 0,46 & & \\
\hline BNT $5 \%$ & \multicolumn{6}{|l|}{0,35} \\
\hline
\end{tabular}

Penambahan ekstrak benih cenderung relatif datar pada variabel berat basah tunas. Hal ini, sama halnya pada variabel jumlah tunas, yaitu bahwa metionin yang mengandung unsur sulfur (belerang) akan menstimulasi tanaman menghasilkan etilen yang akan membuat tanaman lebih cepat masuk pada fase pertumbuhan generatif, yang otomatis membuat pertumbuhan vegetatif menjadi berhenti, sehingga makin tinggi kadar metionin yang diberikan akan mempercepat tanaman itu masuk pada fase generatif yang membuat pertumbuhan vegetatif tidak optimal.

Sama halnya dengan variabel jumlah tunas, ternyata kombinasi perlakuan metionin dan ekstrak benih brokoli tidak berpengaruh yang nyata pada variabel berat basah tunas.

Berat basah tunas tertinggi dicapai pada kombinasi perlakuan tanpa metionin dan ekstrak benih brokoli $2 \mathrm{~g} / \mathrm{l}$, dan yang terendah pada pemberian metionin $20 \mathrm{ppm}$ dan ekstrak benih brokoli $3 \mathrm{~g} / \mathrm{l}$.

\section{3 Tinggi Tunas}

Variabel pengamatan tinggi tunas disajikan pada Tabel 4.

Tabel 4. Nilai Rataan Interaksi Metionin dan Ekstrak Benih terhadap Tinggi Tunas

\begin{tabular}{|c|c|c|c|c|c|c|}
\hline Ekstrak & 0 (EO) & 1 (E1) & 2 (E2) & 3 (E3) & \multirow[b]{2}{*}{ Total } & \multirow[b]{2}{*}{ Rataan } \\
\hline $\begin{array}{c}\text { Metionin } \\
\text { (ppm) }\end{array}$ & \multicolumn{4}{|c|}{ Tinggi Tunas (cm) } & & \\
\hline 0 (M0) & $3,33^{c}$ & 2,21 ab & $2,70 \mathrm{bc}$ & 2,67 bc & 10,91 & 2,73 \\
\hline 10 (M10) & $2,82 \mathrm{bc}$ & 2,18 ab & $2,43^{b}$ & $2,20 \mathrm{ab}$ & 9,63 & 2,41 \\
\hline 20 (M20) & $2,00 \mathrm{ab}$ & $2,05 \mathrm{ab}$ & $2,03 \mathrm{ab}$ & $1,63^{a}$ & 7,71 & 1,93 \\
\hline Total & 8,15 & 6,44 & 7,16 & 6,50 & & \\
\hline Rataan & 2,72 & 2,15 & 2,39 & 2,17 & & \\
\hline BNT $5 \%$ & \multicolumn{6}{|l|}{0,78} \\
\hline
\end{tabular}

Pada Tabel 4 di atas terlihat bahwa pemberian perlakuan pemberian metionin memberi pengaruh yang nyata. Sama halnya dengan variabel jumlah tunas dan berat basah tunas, pemberian metionin pada variabel tinggi tunas berpengaruh negatif, artinya penambahan metionin tidak menaikkan tinggi tunas, tapi justru menurunkan tinggi tunas. Hal ini sama dengan yang terjadi pada variabel jumlah tunas dan berat basah tunas. Pemberian ekstrak benih brokoli dan kombinasi metionin dan ekstrak benih brokoli juga tidak berpengaruh yang nyata pada variabel tinggi tunas.
Tinggi tunas yang paling tinggi dicapai pada kombinasi perlakuan tanpa metionin dan tanpa ekstrak benih brokoli (MOEO), dan yang terendah pada kombinasi perlakuan metionin $20 \mathrm{ppm}$ dan ekstrak benih brokoli $3 \mathrm{~g} / \mathrm{l}$.

\subsection{Jumlah Daun}

Hasil pengamatan jumlah daun dapat dlihat pada Tabel 5. 
Tabel 5. Nilai Rataan Interaksi Metionin dan Ekstrak Benih terhadap Jumlah Daun

\begin{tabular}{|c|c|c|c|c|c|c|}
\hline Ekstrak & $0(\mathrm{EO})$ & 1 (E1) & 2 (E2) & 3 (E3) & \multirow[b]{2}{*}{ Total } & \multirow[b]{2}{*}{ Rataan } \\
\hline $\begin{array}{c}\text { Metionin } \\
(\mathrm{ppm})\end{array}$ & \multicolumn{4}{|c|}{ Jumlah Daun (helaian) } & & \\
\hline $0(\mathrm{MO})$ & $13,22 \mathrm{ab}$ & $16,11 \mathrm{bc}$ & 21,11 bc & $17,33 \mathrm{bc}$ & 67,77 & 16,94 \\
\hline 10 (M10) & $16,67 \mathrm{bc}$ & 10,22 a & 9,22 a & 10,56 a & 46,67 & 11,67 \\
\hline 20 (M20) & 9,89 a & $9,17^{a}$ & $8,33^{a}$ & $7,11^{a}$ & 34,50 & 8,63 \\
\hline Total & 29,78 & 35,50 & 38,66 & 35,00 & & \\
\hline Rataan & 9,93 & 11,83 & 12,89 & 11,67 & & \\
\hline BNT $5 \%$ & \multicolumn{6}{|l|}{6,69} \\
\hline
\end{tabular}

Pada Tabel 5 di atas terlihat bahwa, perlakuan metionin memberi pengaruh yang nyata pada variabel jumlah daun. Pengaruh metionin ialah pengaruh yang negatif, artinya penambahan metionin mengurangi jumlah daun. Hal ini sama pada variabel jumlah tunas, berat basah tunas, dan tinggi tunas.

Pemberian ekstrak benih brokoli tidak berpengaruh yang nyata pada variabel jumlah daun, begitu dengan kombinasi perlakuan metionin dan ekstrak benih brokoli. Hal ini boleh terjadi, sama seperti pada variabel jumlah tunas, berat basah tunas, dan tinggi tunas.

Jumlah daun terbanyak dicapai pada perlakuan tanpa metionin dan tanpa ekstrak benih brokoli (MOEO). Jumlah daun sedikit dicapai pada kombinasi perlakuan metionin 20 ppm dan ekstrak benih brokoli $3 \mathrm{~g} / \mathrm{I}$ (M20E3).

\subsection{Kandungan Sulforafan}

Hasil pengamatan terhadap kandungan sulforafan seperti tertera pada Tabel 6. Pada Tabel 6 dapat dilihat bahwa pemberian metionin memberi pengaruh yang sangat nyata pada kandungan sulforafan. Pemberian ekstrak benih brokoli memberi hasil yang berpengaruh sangat nyata pada variabel kandungan sulforafan. Kombinasi perlakuan metionin dan ekstrak benih brokoli berpengaruh yang sangat nyata pada variabel kandungan sulforafan. Apabila dilihat pada masing-masing taraf metionin meningkatkan kandungan sulforafan jika ditambah dengan ekstrak benih. Hal ini diduga disebabkan oleh metionin yang ditambahkan merupakan prekursor dari glukorafan, dan glukorafan juga merupakan prekursor dari sulforafan. Jelas di sini, penambahan metionin akan meningkatkan kandungan sulforafan.

Tabel 6. Nilai Rataan Interaksi Metionin dan Ekstrak Benih terhadap Kandungan Sulforafan

\begin{tabular}{|c|c|c|c|c|c|c|}
\hline Ekstra & $0(\mathrm{EO})$ & 1 (E1) & $2(\mathrm{E} 2)$ & $3(\mathrm{E} 3)$ & \multirow[b]{2}{*}{ Total } & \multirow[b]{2}{*}{ Rataan } \\
\hline $\begin{array}{c}\text { Metionin } \\
\text { (ppm) }\end{array}$ & \multicolumn{4}{|c|}{ Kandungan sulforafan (ng/ml) } & & \\
\hline $0(\mathrm{MO})$ & $26,05^{d}$ & 32,59 e & $23,39 \mathrm{~cd}$ & $9,58^{a}$ & 91,610 & 22,903 \\
\hline 10 (M10) & 7,39 a & $18,38^{b}$ & 20,89 bc & $86,62^{\text {h }}$ & 133,286 & 33,322 \\
\hline 20 (M20) & $8,00^{a}$ & $47,51^{f}$ & $49,60^{f}$ & $57,35 \mathrm{~g}$ & 162,457 & 40,614 \\
\hline Total & 41,440 & 98,483 & 93,883 & 153,547 & & \\
\hline Rataan & 13,813 & 32,828 & 31,294 & 51,182 & & \\
\hline BNT $5 \%$ & \multicolumn{6}{|l|}{3,78} \\
\hline
\end{tabular}

Pandiangan (2010) menyatakan bahwa penambahan prazat (prekursor) merupakan salah satu cara untuk meningkatkan kandungan metabolit sekunder dalam kultur jaringan tumbuhan, misalnya aktivitas antikanker katarantin pada sel Mouse Mammary (Pandiangan, et al., 2008), pertumbuhan dan kandungan katarantin kultur agregat sel
Catharanthus roseus yang diberi tryptophan (Pandiangan, 2010), dan peningkatan produksi katarantin melalui teknik elisitasi (Pandiangan, 2011).

Pemberian ekstrak benih yang juga sudah mengandung glukorafan akan meningkatkan kandungan sulforafan, dan setelah bersama-sama 
dengan metionin yang diberikan akan lebih meningkatkan kandungan sulforafan. Kandungan sulforafan tertinggi dicapai pada kombinasi perlakuan metionin $10 \mathrm{ppm}$ dan ekstrak benih brokoli $3 \mathrm{~g} / \mathrm{I}$ (M10E3), dan yang terendah dicapai pada kombinasi perlakuan metionin $10 \mathrm{ppm}$ dan perlakuan tanpa ekstrak benih brokoli (M10E0).

\section{Kesimpulan}

Hasil penelitian ini dapatlah ditarik kesimpulan sebagai berikut :

1. Pemberian metionin memberikan pengaruh pada pertumbuhan tanaman brokoli, pemberian ekstrak benih brokoli dan interaksi metionin dan ekstrak benih brokoli tidak mempengaruhi pertumbuhan tanaman brokoli.

2. Pemberian metionin dan ekstrak benih brokoli meningkatkan kandungan sulforafan, dan kombinasi perlakuan pemberian metionin dan perlakuan ekstrak benih brokoli lebih meningkatkan kandungan sulforafan, kandungan tertinggi dicapai pada kombinasi perlakuan metionin 10 ppm dan ekstrak benih brokoli $3 \mathrm{~g} / \mathrm{I}$ (M10E3).

\section{Daftar Pustaka}

Anonim, 2009. Brokoli. http://www.iptek.net.id/ind/ pd_tanobat/view.php?mnu =2\&id=207. (Diakses pada hari Senin tanggal 20 Februari 2009 pukul 09.00 WIB).

Dharlimantha, 2007. 'Atlas Tumbuhan Obat Indonesia Jilid 2'.
Ding, T. J., L. Zhou, and X. P. Cao. 2006. A Facile and Green Synthesis of Sulforaphane. Chinese Chemical Letters Vol. 17, No. 9, pp 1152-1154, 2006 Sate Key Laboratory of Applied Organic Chemistry and College of Chemistry and Chemical Engineering, Lanzhou University, Lanzhou 730000.

Fowler, M.W. 1983. Commercial Application and Economic Aspect of Mass Plant Culture. Dalam : Plant Biotechnology, Mantell $\mathrm{S}>\mathrm{H}$ and H.Smith. Cambrige University, London.

Pandiangan, D. dan W. Tilaar. 2007. Peningkatan Kandungan Katarantin Dengan penambahan Phytium aphanidermatum sebagai Teknik Elisitasi. Laporan Penelitian Fundamental Unsrat.

Pandiangan, D., R. Esyanti, dan E. De Queljoe. 2008. Aktivitas Antikanker Katarantin pada Sel Mouse Mammary Cancer MmT06054. Jurnal IImiah Sains Vol. 8 No. 1, April 2008.

Pandiangan, D. 2010. Hubungan antara Kandungan IAA dengan Pertumbuhan dan Kandungan Katarantin Kultur Agregat Sel Catharanthus roseus yang Diberi Perlakuan Tryptophan dalam Labu Erlenmeyer. Jurnal IImiah Sains Vol. 10 No. 2, Oktober 2010.

Pandiangan, D. 2011. Peningkatan Produksi Katarantin melalui Teknik Elisitasi pada Kultur Agregat Sel Catharanthus roseus. Jurnal IImiah Sains Vol. 11 No. 2, Oktober 2011.

Sowy, M. A. 1984. Penelitian dan Pengembangan Kubis Bunga di Balai Penelitian Hortikultura Lembang. Fakultas Pertanian, IPB. Bogor. 